\title{
Region wise referrals to a tertiary care centre: a retrospective analysis
}

\author{
Sirisha Paidi*, Aashritha Thonangi
}

Department of Obstetrics and Gynecology, Andhra Medical College, King George Hospital, Visakhapatnam, Andhra Pradesh, India

Received: 04 October 2019

Accepted: 08 November 2019

\section{*Correspondence:}

Dr. Sirisha Paidi,

E-mail: siree_swapna@yahoo.com

Copyright: () the author(s), publisher and licensee Medip Academy. This is an open-access article distributed under the terms of the Creative Commons Attribution Non-Commercial License, which permits unrestricted non-commercial use, distribution, and reproduction in any medium, provided the original work is properly cited.

\section{ABSTRACT}

Background: Emergency obstetric care in health care requires a linked referral system to be effective in reducing maternal morbidity and mortality. This review is aimed at summarizing the proportion of referrals from urban, rural and tribal areas of surrounding districts to tertiary care centre, King George Hospital, Visakhapatnam for a 6 month period; from May 2018 to October 2018.

Methods: Retrospective study done at a tertiary care teaching hospital, including 3157 cases referred from the surrounding urban, rural and tribal areas.

Results: Out of the 3157 referred cases, most of them (1658) were from rural areas, 1030 from urban and 469 from tribal areas. Referrals done in view of post caesarean pregnancies were more in urban and rural areas whereas more preeclampsia and anaemia cases were referred from tribal areas. Various indications of referral are documented. Majority of them were unbooked cases.

Conclusions: Specific guidelines regarding whom to refer, how to refer and when to refer would be helpful in making timely referral. These would also help to decrease the burden on the tertiary care centers which deal with a huge caseloads in spite of limited infrastructure and manpower. Adequate attention and better care can be given to complicated cases if the total case load is reduced. Stringent documentation in referral slip and better co-ordination are required for a strong health care system.

Keywords: Maternal morbidity and mortality, Maternal outcome, Obstetrics referrals

\section{INTRODUCTION}

Referral services are essential for identification and referral of high-risk pregnancies in maternal and child health care. In developing countries like India, this aspect of health system remains weak. ${ }^{1}$ Patients in difficult terrains may not be able to reach the nearby hospital when risk is anticipated. Referrals to a tertiary care centre include those from urban, rural and tribal populations.

The 3-tier health care delivery system was conceived in such a manner that the patients in need of higher level of expertise and care could be referred accordingly from primary or secondary centres directly to a tertiary level centre.

A study showed that $92 \%$ of maternal deaths are due to delay in referral and case management. ${ }^{2}$ The prevention of maternal mortality (PMM) network study has proposed a three delays model for referrals in obstetric and gynaecological emergencies; first delay is in deciding to seek medical care, second delay is in identifying and reaching a medical facility, third delay is in receiving adequate and prompt treatment even after reaching a care 
institution. ${ }^{3,4}$ The second delay is especially seen in rural and tribal populations where travel, cost and ignorance are major factors. The third delay is seen in institutions where in, there is a doctor-patient disproportion, high case load with limited resources and delayed referral done after the golden period, when patient is already in an irretrievable condition.

Although most obstetric complications (defined as acute conditions such as postpartum haemorrhage, sepsis, eclampsia, and obstructed labour) that can cause maternal death may not be easily predicted, the majority can be treated with timely provision of a combination of evidence-based interventions known as emergency obstetric care (EmOC). ${ }^{5,6}$ The availability of EmOC is considered to be an indicator of the preparedness of a health care system in managing conditions leading to acute maternal morbidity and mortality. ${ }^{7,8}$

Emergency obstetric care EmOC refers to elements of obstetric care needed for management of complications during pregnancy, delivery and postpartum period, skilled personnel, equipment and support services. EmOC services are of paramount importance in reducing maternal mortality and morbidity. It is still recommended to electively refer pregnant woman with previous caesarean section, hypertension, severe anaemia, diabetes mellitus, breech presentation, transverse lie and multiple gestation for delivery before any complication arise to a well-equipped health care centre where all possible complications can be managed well.

With this background, our study was undertaken to evaluate the pattern of obstetric cases referred to tertiary teaching hospital and maternal outcomes amongst referred patients from various regions.

\section{METHODS}

Retrospective observational study. A total 6-month period from May 2018 to October 2018. All Obstetrics cases referred to the Department of Obstetrics and Gynaecology, King George Hospital, (a tertiary care hospital in Visakhapatnam) from urban, rural and tribal areas of the surrounding districts.

The study data was collected from case sheets of the patients referred and managed at the above-mentioned tertiary teaching hospital. Detailed clinical history, place of referral, type of transport used, and indications of referral were studied. Findings of physical and obstetric examination and reports of relevant investigations were noted. Management of the patient, clinical course, and maternal outcome was documented.

\section{Statistical analysis}

Descriptive statistics like percentages were used for analysis.

\section{RESULTS}

A total of 5507 patients were admitted in the department of Obstetrics, King George Hospital, Visakhapatnam during the study period; out of which 3157 (57\%) were referred from other centres (Figure 1).

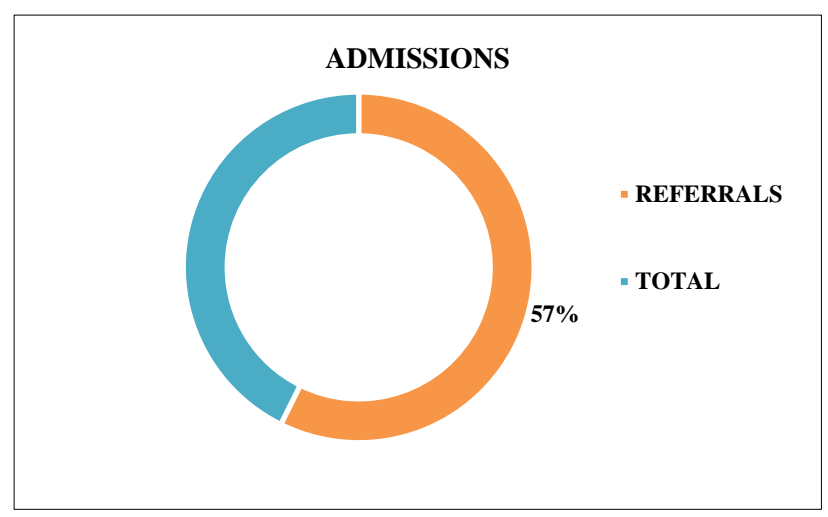

Figure 1: Proportion of referrals in total admissions to Department of Obstetrics and Gynaecology, King George Hospital (May - October 2018).

Table 1: Distribution of referral cases according to age, Department of Obstetrics and Gynaecology, King George Hospital (May - October 2018).

\begin{tabular}{|lll|}
\hline Age (years) & Number of cases & $\%$ \\
\hline$<20$ & 537 & 17 \\
\hline $20-30$ & 2399 & 76 \\
\hline$>30$ & 221 & 7 \\
\hline
\end{tabular}

Table 2: Distribution of referral cases according to parity, Department of Obstetrics and Gynaecology,

King George Hospital (May - October 2018).

\begin{tabular}{|lll|}
\hline Parity & Number of cases & $\%$ \\
\hline Primi & 1528 & 48.4 \\
\hline Multi & 1361 & 43.1 \\
\hline Grand multi & 268 & 8.5 \\
\hline
\end{tabular}

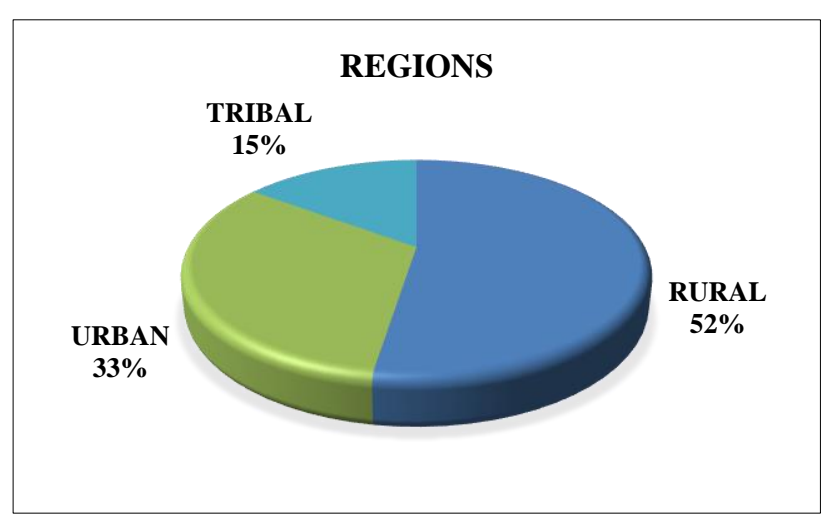

Figure 2: Distribution of referral cases according to regions, Department of Obstetrics and Gynaecology, King George Hospital (May - October 2018). 
Maximum number of cases in our study were in the age group 20-30 years, comprising $76 \%$ of total cases. (Table 1 ). $7 \%$ of them belonged to age $>30$ years and $17 \%$ to age $<20$ years. $48.4 \%$ of cases in our study were primi gravida and $8.5 \%$ were grand multi gravida with equal to more than 5 pregnancies (Table 2).

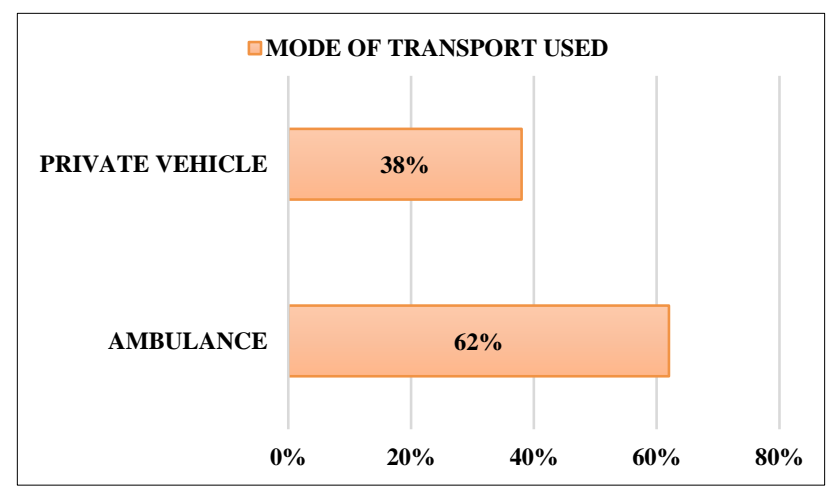

Figure 3: Distribution of referral cases according to mode of transport used, Department of Obstetrics and Gynaecology, King George Hospital (May - October 2018).

There were 1658 cases, i.e., about $52.52 \%$ of the cases were referred from rural areas, followed by $32.63 \%$ from urban areas and $14.85 \%$ from tribal areas, (Figure 2). Mode of transport used by the referred patients were hospital ambulances and private vehicles (Figure 3). 62\% of the referred patients reached our medical facility in hospital ambulances.

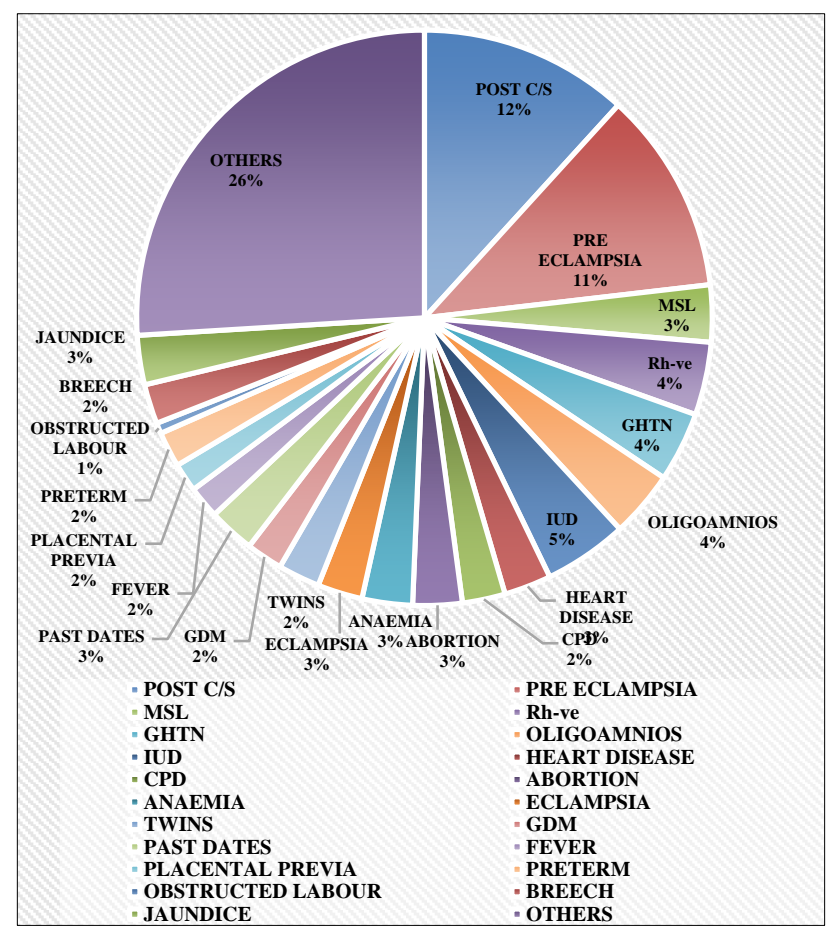

Figure 4: Indications for referral cases from rural areas to Department of Obstetrics and Gynaecology,

King George Hospital (May - October 2018).

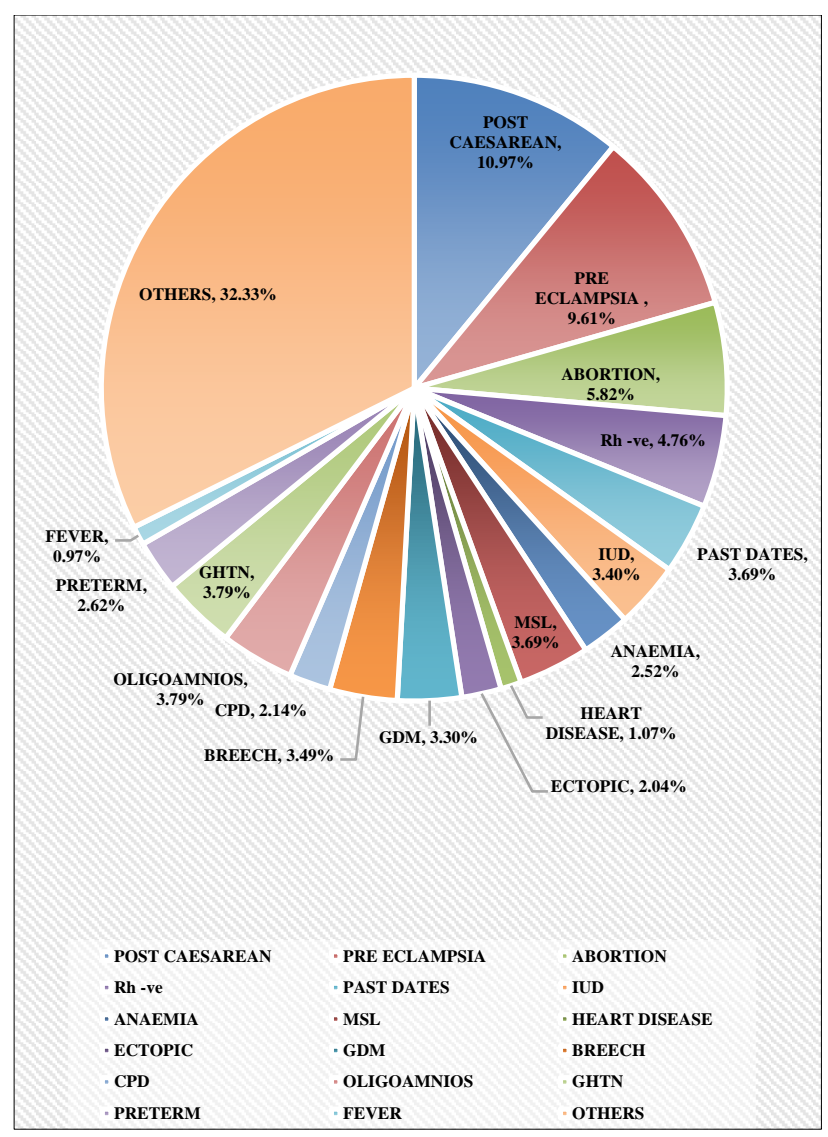

Figure 5: Indications for referral cases from urban areas to Department of Obstetrics and Gynaecology,

King George Hospital (May - October 2018).

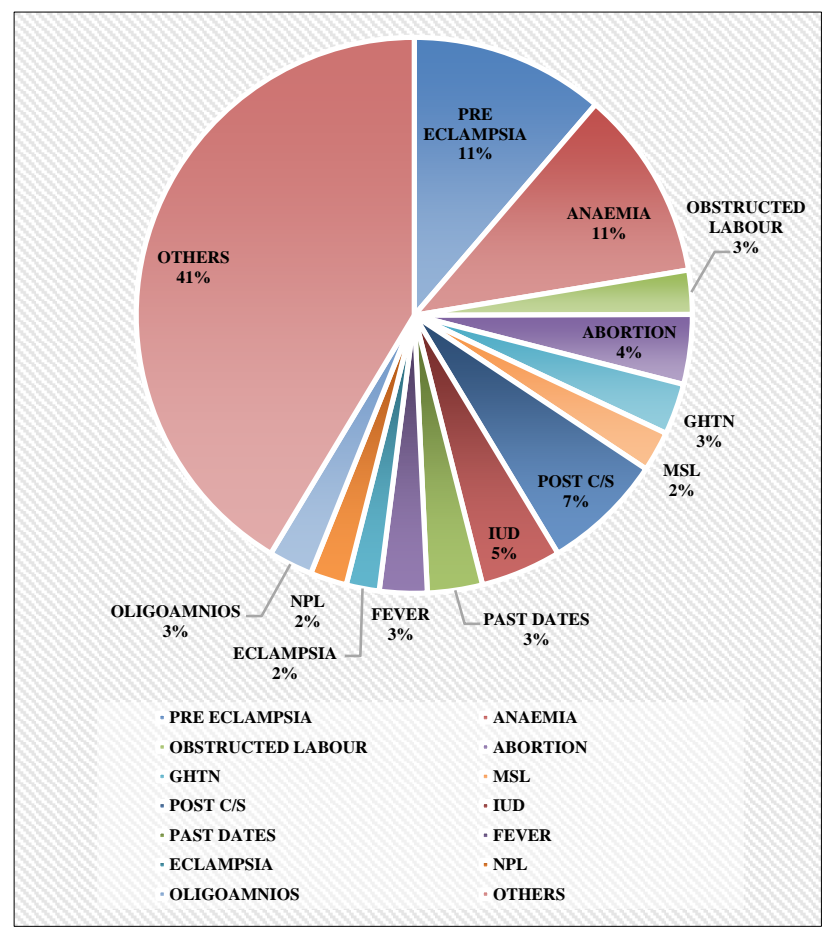

Figure 6: Indications for referral cases from tribal areas to Department of Obstetrics and Gynaecology, King George Hospital (May - October 2018). 
Post caesarean (12\%), hypertensive disorders of pregnancy $(11 \%)$ were the major indications for referral from rural areas (Figure 4). Post caesarean (10.67\%), hypertensive disorders of pregnancy $(9.61 \%)$ were the major indications of referral from urban areas (Figure 5). Hypertensive disorders of pregnancy (11\%), anaemia $(11 \%)$ were the major causes of referral from tribal areas (Figure 6). About 26.19\% of cases were referred for lack of functional Operation Theatres, Blood banks, round the clock anaesthesia services and competent gynaecologists. Other indications include cord prolapse, hand prolapse, ectopic, precious pregnancy, malpresentations, $\mathrm{Hbs} \mathrm{Ag}$ positive, gastroenteritis, epilepsy, other medical disorders and complications.

Uncomplicated cases were also referred from all these areas; those from rural superseded those from urban and tribal areas. This is probably due to lack of round the clock obstetric care at various levels.

\section{Maternal deaths}

Out of 43 maternal deaths, 38 cases $(88.37 \%)$ were referred from various regions while 5 cases were those which were directly admitted in our institution.

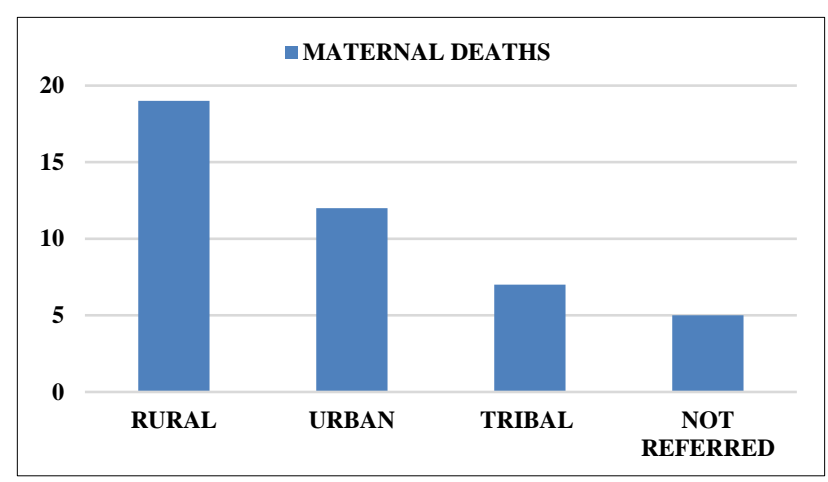

Figure 7: Maternal deaths in the Department of Obstetrics and Gynaecology, King George Hospital (May - October 2018).

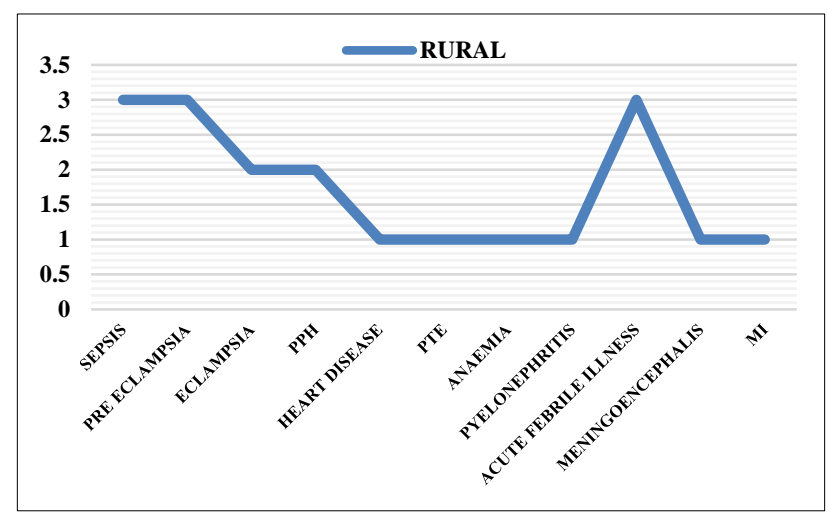

Figure 8: Causes of maternal deaths in cases referred from rural areas to the Department of Obstetrics and Gynaecology, King George Hospital (May - October 2018).
A total of 19 cases were from rural areas, 12 cases from urban areas and 7 cases from tribal areas. (Figure 7). Preeclampsia, sepsis and acute febrile illness accounted for most of maternal deaths in referred cases (Figure 8, 9 and 10). Others include PPH, heart disease, anaemia, pulmonary thromboembolism, myocardial infarction, meningomyelitis, pyelonephritis. Hypertensive disorders of pregnancy constitute the leading cause of maternal deaths $(23.68 \%)$ amongst the referred cases.

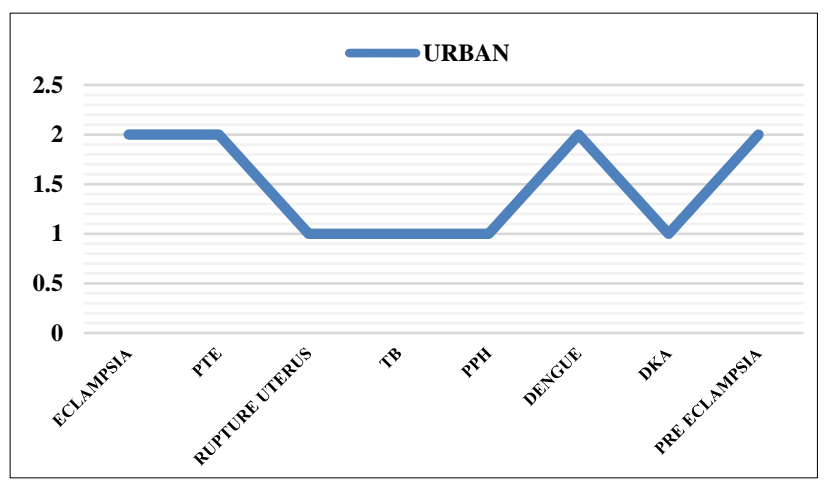

Figure 9: Causes of maternal deaths in cases referred from urban areas to the Department of Obstetrics and Gynaecology, King George Hospital (May - October 2018).

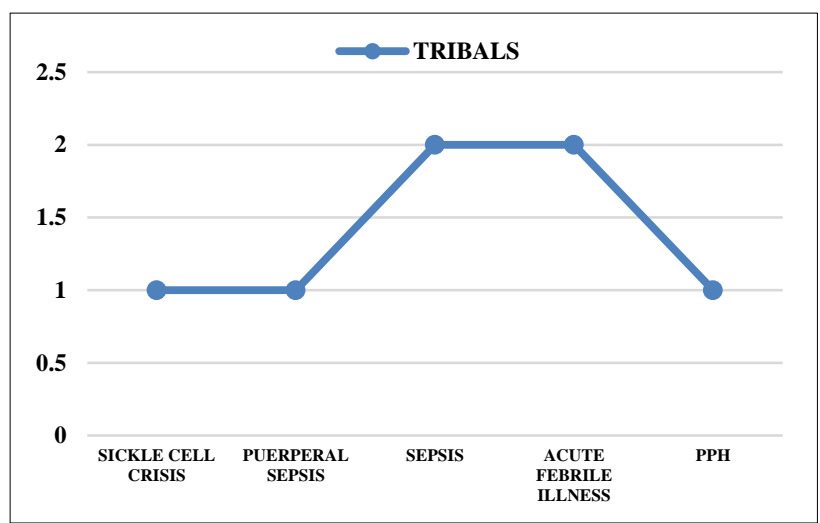

Figure 10: Causes of maternal deaths in cases referred from tribal areas to the Department of Obstetrics and Gynaecology, King George Hospital (May - October 2018).

\section{DISCUSSION}

King George Hospital is a tertiary care teaching hospital attached to Andhra Medical College, Visakhapatnam, Andhra Pradesh, India. Obstetrics cases (both complicated and simple) are referred from various primary and secondary health care centres, private hospitals of not only Visakhapatnam but from surrounding districts as well.

The World Health Organization estimates that at least 88$98 \%$ of maternal deaths can be averted with timely access to existing, emergency obstetric care using effective and 
efficient referral systems. ${ }^{9}$ Timeliness and appropriateness of referral are a challenge to obstetricians, since the delay in referral affects the maternal and perinatal outcome adversely, hence identification of "at risk" patients and obstetric emergencies and timely referral is of immense importance.

Alka $\mathrm{P}$ et al in their study noted $24.16 \%$ of cases were referred. ${ }^{10}$ However the proportion of referred cases in our study was $57 \%$.

Banu $\mathrm{M}$ et al on assessing the overall age distribution found that majority (74\%) of the respondents were between $20-35$ years. ${ }^{11}$ Similarly in our study, the maximum number of patients $(76 \%)$ were in the $20-30$ years of age group.

Gupta PR et al, found $52.17 \%$ patients were primigravida, which is comparable to $48.4 \%$ primigravida cases in our study. ${ }^{12}$

In a study conducted by Vinayak NM et al, only $11 \%$ patients travelled by ambulance. ${ }^{13}$ In our study, $62 \%$ of patients travelled by hospital ambulances, rest $38 \%$ patients used their private vehicles. Arranging a private vehicle when faced with obstetric emergency necessitating referral takes time and costs money.

Patel HC et al, in their study found that indications for referral were preeclampsia (16\%), MSL (5\%). ${ }^{14}$ In our study, however, Post caesarean (12\%) followed by hypertensive disorders of pregnancy $(11 \%)$ were the major indications for referral from rural areas. Post caesarean $(10.67 \%)$ followed by hypertensive disorders of pregnancy $(9.61 \%)$ were the major indications for referral from urban areas. Hypertensive disorders of pregnancy $(11 \%)$ and anaemia $(11 \%)$ were the major indications for referral from tribal areas.

Previous caesarean section was the cause of reference in $10-14 \%$ of cases from rural, urban and tribal areas in our study, which is comparable to the study conducted by Khatoon A et al, where previous caesarean section was the cause of reference in $15 \%$ of cases. ${ }^{12,15}$ The patients with previous caesarean section are referred to higher centres from $\mathrm{PHC} / \mathrm{CHC}$ due to unavailability of operation theatre, gynaecologists, anaesthetics, trained staff or basic infrastructure deficits.

A total of 43 maternal deaths were reported during the study period, of which 38 (i.e. $88.37 \%$ ) were referred. This shows delay in referral of complicated cases from our peripheral health centres, which could be due to lack of adequate transport facilities or trained personnel in $\mathrm{PHC} / \mathrm{CHC}$. Delay in referral is a big contributing factor for adverse maternal outcome. The leading cause of maternal mortality amongst referred cases in our study was hypertensive disorders and their complications.
Similar results were found by Begum $S$ et al in their study. ${ }^{16}$

Increased rate of caesarean sections with improper indications, sections done at patients' request or relatives' apprehension and compulsion are main reasons for increased rate of post caesarean pregnancies apart from delayed referrals of patients with meconium stained liquor and fetal distress. Lack of knowledge, poor peripheral care, and lack of regular antenatal checkups increased the ratesof complications in cases of preeclampsia. Poor nutritional status and inadequate spacing of pregnancy compounded by inability of poor patients to have adequate diet due to economic reasons leads to high rate of anaemia in pregnancy. Unavailability of blood transfusion facilities in case of severe anaemia at PHC's and CHC's may also contribute to such high percentage of patients being referred to our tertiary care hospitals.

In our study, many cases were referred for lack of wellequipped operation theatres, blood banks and competent gynaecologists and anaesthesiologists. Government should take adequate measures to improve health care infrastructure, make provisions for developing new blood banks and appoint trained gynaecologists and anaesthesiologists in the peripheries to reduce the burden on tertiary care centres.

\section{CONCLUSION}

Peripheral health care system needs to be strengthened and practice of early referral needs to be implemented for better maternal outcome. Provision of a dedicated ambulance meant solely for transport of referred patients in every area from which patients are referred is desirable. Health education to the community, better antenatal care up to grass root level, emergency intranatal care, availability of services of skilled birth attendants, well organized first referral centre with better transportation facility, availability of blood round the clock, anaesthesia services, and availability of specialist in the field of obstetrics at the referral unit in rural, urban and tribal areas will definitely reduce maternal morbidity and mortality. Availability of specialists and facilities in difficult terrains is of utmost importance.

Specific guidelines regarding whom to refer, how to refer and when to refer would be helpful in making timely referral. These also help to decrease the burden on the tertiary care centre dealing with high case load and limited resources. Adequate attention and better care can be given to complicated cases if the total case load is reduced. Stringent documentation in referral slip and better co-ordination are required for a strong health system.

\section{ACKNOWLEDGMENTS}

Authors would like to thank colleagues and residents for their support and cooperation. 
Funding: No funding sources

Conflict of interest: None declared

Ethical approval: The study was approved by the Institutional Ethics Committee

\section{REFERENCES}

1. Park K. Textbook of Preventive and Social Medicine $17^{\text {th }}$ ed. Jabalpur. Banarasidas Bhanoj Publishers; 2000:632.

2. Thaddeus S, Maine D. Too far to walk: maternal mortality in context. Soci Sci Med. 1994;38:1091110.

3. Brun JL, Billeaud C, Elleau C, Guyon F, Roux D, Dallay D, et al. Maternal transport to the Bordeaux University Hospital: a retrospective study of 263 cases (1996-1998). J Gynecol Obstet Biol Reprod. 2000;29(4):414-22.

4. Swain S, Prakash A. Utilisation of referral services by high risk pregnant population in rural Varanasi. Indian J Matem Child Health. 1992;3:74-6.

5. Koblinsky M, Chowdhury ME, Moran AC, Ronsmans C. Maternal morbidity and disability and their consequences: neglected agenda in maternal health. J Health Popul Nutr. 2012;30:124-30.

6. Lee AC, Lawn JE, Cousens S, Kumar V, Osrin D, Bhutta ZA, et al. Linking families and facilities for care at birth: what works to avert intrapartum related deaths? Int J Gynaecol Obstet. 2009;107(1):65-8.

7. Travis P, Bennett S, Haines A, Pang T, Bhutta Z, Hyder AA, et al. Overcoming health-systems constraints to achieve the millennium development goals. Lancet. 2004;364:900.

8. Paxton A, Bailey P, Lobis S. The United Nations process indicators for emergency obstetric care: reflections based on a decade of experience. Int $\mathrm{J}$ Gynaecol Obstet. 2006;95:192-208.
9. World Health Organization. Maternal Health and Safe Motherhood Programme. Mother-baby package: implementing safe motherhood in countries: practical guide. $1996 . \quad$ Available at: https://apps.who.int/iris/handle/10665/63268.

10. Puri A, Yadav I, Jain N. Maternal mortality in an urban tertiary care hospital of North India. J Obstet Gynaecol India. 2011;61(3):280-5.

11. Morsheda B, Shamsun N, Hashima EN. Assessing the MANOSHI referral system addressing delays in seeking emergency obstetric care in Dhaka's Slums. MANOSHI working paper series Manoshi- WP10:136 published by ICDDR, B, BRAC; 2010:10.

12. Gupta PR, Chaudhary SN, Gonnade NV. Maternal and fetal outcome in referred patients to tertiary care center. Sch J App Med Sci. 2016;4(5C):1624-63.

13. Vinayak NM, Panditrao SK, Ramkrishna MA Critical study of referrals in obstetric emergencies. J Obstet Gynaecol India. 2004;54(3):258-9.

14. Patel HC, Singh BB, Moitra M, Kantharia SL. Obstetric referrals: scenario at a primary health centre in Gujarat. Natl $\mathbf{J}$ Community Med. 2012;3(4):711-4.

15. Khatoon A, Hasny SF, Irshad S, Ansari J. An audit of obstetrics referrals to Abbasi Shaheed Hospital. Pak J Surg. 2011;27(4):304-8.

16. Begum S, Aziz-un-Nisa I. Analysis of maternal mortality in a tertiary care hospital to determine causes and preventable factors. J Ayub Med Coll Abbottabad. 2003;15(2):49-52.

Cite this article as: Paidi S, Thonangi A. Region wise referrals to a tertiary care centre: a retrospective analysis. Int J Reprod Contracept Obstet Gynecol 2019;8:4678-83. 